\title{
Risk Migration in Supply Chain Inventory Financing Service
}

\author{
Zheng Qin ${ }^{1}$, Xiaochao Ding ${ }^{2}$ \\ ${ }^{1}$ School of Information Management and Engineering, Shanghai University of Finance and Economics, Shanghai, China; ${ }^{2}$ Informa- \\ tion Engineering College of Yangzhou University, Yangzhou, China. \\ Email: \{morris.brenna, federica.foiadelli, dario.zaninelli\}@polimi.it, cristina.roscia@unibg.it
}

Received January $17^{\text {th }}, 2010$; revised March $17^{\text {th }}$, 2011; accepted April $7^{\text {th }}, 2011$.

\begin{abstract}
Inventory financing affects the risks of both for banks and supply chain companies. Traditionally, supply chain research focus more on material flow than financial. We construct a supply chain financing risk-information migration model $(R M M)$. In this model, we discussed the preconditions to adopt inventory financing when the enterprises are facing cash constraints. And we simulated the whole operate of supply chain and bank behavior with Matlab. The simulation result shows if loan conditions are satisfied, the total risk value is reduced. Risk migration happens in the financing process. In this process, information-risk proportions are more reasonable.
\end{abstract}

Keywords: Supply Chain, Inventory Financing, Value of Risk

\section{Introduction}

Modern corporate finance theory is founded on the proposition that financial capital is supplied to firms by investors who have an "expectation of return", and that, Cavinato (1991) research show supply chain can reduce cost, improve quality and make lead time shorter [1], thus it can improve competence of the whole supply chain. In traditional supply chain, researchers focus more on material flow than cash flow. It is essential to corporate supply chain research with finance theory. Reciprocally, such expectation represents the firm's "cost of financial capital” optimization along with materials in supply chain operation. We observe that supply chain theory begins with "irrelevancy" pronouncements about a firm's value being independent of its supply chain optimization. Risk sharing in supply chain financing, which are ignored in most supply chain optimization, in response to these unrealistic assumption, theoretical development has subsequently come to be directed at providing models that are descriptive of the way corporate financial with supply chain [2]. To this end, supply chain financial has increasingly been recognized as first order.

Supply chain structure is defined as the associations among supply chain members [3]; this structure can benefit both vertical and horizontal connected companies

The work is supported by China National Nature Science Foundation under Grant 70971083.
[4]. Aberdeen Group defines Supply Chain Finance (SCF) as "a combination of Trade Financing provided by a financial institution, a third-party vendor, or a corporation itself, and a technology platform that unites trading partners and financial institutions electronically and provides the financing triggers based on the occurrence of one or several supply chain events.” Banks can offer SCF solutions that enable their customers to lower costs and create financial stability in their end-to-end supply chain-and create deeper and broader customer relationships in the process.

Inventory financing is a kind of supply chain finance, which is banking line of credit secured by the company's inventory. Companies with tangible inventory and a proven sales history and good credit since lenders aren't really interested in taking possession of your inventory if you can't make your loan payments. John A. Buzacott \& Rachel Q. Zhang (2004) researched on the deposit and loan decision process of supply chain companies and banks [2]. N. R. Srinivasa Raghavan and Vinit Kumar Mishra (2009) consider a two-level supply chain with a single retailer and a manufacturer, where both the firms are facing financial constraints and cannot produce/order their optimal quantity [5].

A commonly held opinion is that the low level of long-term profit rates could be largely explained by a decline in the compensation for risk. This opinion is 
supported by a great deal of empirical work devoted to the measurement of bond risk premium and the analysis of their dynamics [6]. While financing a firm, although a lender tries to perceive its exposure to default risk by looking into borrower's accounts, due to lack of proper information, the buying or selling capacities of preceding or following stakeholders, as in manufacturer and its retailer of supply chain remain unknown. Lender's analysis is then based on certain assumptions. This lack of information is a reality, especially for small firms that are not publicly listed.

The paper is organized as follows. In Section 2 we introduce basic notation, terminology and assumptions. The risk information migration model RMM model and solutions is presented in Section 3. We discuss inference and parameter estimation for RMM and presented experiment results in Section 4. Finally, Section 5 presents our conclusions.

\section{Assumptions, Notations}

For simplicity we assume that both the firms have no other assets but the cash available with them before they commence their respective activities. Both manufacture and retailer have no fix asset such as land, buildings, machines etc. Account payable, account receivable, cash, inventory and short term borrowing are considered in the model. $q_{r}$ are predicted based on constant elasticity form. The expected quantity of production is equal with mathematical expectation of $q_{r}\left(\tilde{q}_{m}=E\left(q_{r}\right)\right)$. Because of cash constraints and ability to get loan from bank, real quantity is less than expected quantity. Manufacture firstly predicts the retailer's purchasing before producing, and decides a price $p_{m}$ of finished product. Based on the cash constraints of manufacture, $L_{i m}$ will be decided. Bank will evaluate the risk and give a max loan available for bank. Retailer predicts a market demand and purchase from manufacture. At any time, cash owned by manufacture and retailer greater than zero, or they will bankrupt.

$V a R$ is adopted to calculate risk value of manufacture and bank loan. It is equal the maximum loss from the specific confidence level. Based on Jorion, 1997, we can calculate VaR with Equations (1) and (2) [7].

$$
\begin{aligned}
& \operatorname{VaR}_{L}=E\left(\Pi_{L}\right)-\Pi_{L}^{*} \\
& \operatorname{VaR}_{M}=E\left(\Pi_{M}\right)-\Pi_{M}^{*}
\end{aligned}
$$

A simple two-stage supply chain is considered that consisting of a single manufacturer and a retailer. Manufacture produces goods at a constant rate and ships it to retailer with zero lead time. Retailer is of the classical newsvendor type. Retailer returns the defective quantity to manufacture who is liable to compensate for it at the end of the period. One bank provides loans to both manufacture and retailer if they applied and passed evaluation of risk level.

$\begin{array}{cl}i & \text { Interest rate of bank } \\ i^{\prime} & \text { Interest rate of deposit where } i^{\prime}<i \\ x_{m} & \text { Current cash of manufacture } \\ p_{r m} & \text { Price of raw material manufacture bought from supplier } \\ I_{r m}(t) & \text { Raw material inventory of manufacture } \\ c_{l} & \text { Production cost of manufacture } \\ \tilde{\Pi}_{L} & \text { Expected profit without inventory finance } \\ \Pi_{L} & \text { Real profit without inventory finance } \\ \tilde{\Pi}_{L}{ }_{L} & \text { Expected profit with inventory finance } \\ \Pi_{L}^{\prime} & \text { Real profit with inventory finance } \\ \tilde{q}_{m} & \text { Expected quantity of product being produced by manu- } \\ q_{m} & \text { facture } \\ q_{r} & \text { Real quantity need to be produced by manufacture } \\ p_{r m} & \text { Price of raw material } \\ p_{m} & \text { Price of product manufacture selling to retailer } \\ x_{S} & \text { Current cash of retailer } \\ \alpha & \text { Coefficient of labor changing to product } \\ y_{m} & \text { Account receivable of manufacture } \\ y_{s} & \text { Account receivable of retailer } \\ L_{o m} & \text { After risk evaluation, lend available from bank to } \\ L_{i m} & \text { manufacture } \\ z_{m} & \text { After analysis of market information, load applied from } \\ z_{S} & \text { Accounts payable of manufacture } \\ I_{f m} & \text { Finished product inventory of manufacture } \\ V_{M} R_{L} & \text { Value at risk of retailer in borrowing from bank } \\ \theta_{L} & \text { Value at risk of manufacture in borrowing from bank } \\ \theta_{M} & \text { The portion of VaR of bank loan after standardized } \\ & \text { dardized }\end{array}$

\section{The Model}

\subsection{Bank Profit from Loan}

The cost of bank cash is equal $i^{\prime}$, thus the cost of manufacture cash is $i$. Based on maximum expectation of return principle, we can easily get condition of $i^{\prime}<i$. The bank can predict the payable of manufacture after one period of product time.

$$
\text { Payable }_{m} \leq \min \left\{\tilde{q}_{m}, q_{r}\right\} p_{m}
$$

If manufacture apply loan from bank without mortgage, the expected profit of bank as follow:

$$
\tilde{\Pi}_{L}=\min \left\{L_{o m}(1+i), \min \left\{\tilde{q}_{m}, q_{r}\right\} p_{m}\right\}-L_{o m}\left(1+i^{\prime}\right)
$$

By the profit function 4, when $L_{\text {om }}(1+i)<$ 
$\min \left\{\tilde{q}_{m}, q_{r}\right\} p_{m}$ bank can get more profit by improve $L_{\text {от }}$. When $L_{\text {от }}(1+i)>\min \left\{\tilde{q}_{m}, q_{r}\right\} p_{m}$, no matter how much bank loans, bank will loss profit. So the maximize bank profit and exist conditions show as follow:

$$
\left\{\begin{array}{l}
\max \left(\tilde{\Pi}_{L}\right)=\min \left\{\tilde{q}_{m}, q_{r}\right\} \frac{i-i^{\prime}}{1+i} \\
L_{o m}=\left(\min \left\{\tilde{q}_{m}, q_{r}\right\} p_{m}\right) /(1+i) \\
L_{o m}(1+i) \geq \min \left\{\tilde{q}_{m}, q_{r}\right\} p_{m} \geq L_{o m}\left(1+i^{\prime}\right)
\end{array}\right.
$$

When adding inventory mortgage to exist bank profit functions, we can get the object function of bank profit is:

$$
\left\{\begin{aligned}
\tilde{\Pi}_{L}^{\prime}= & \min \left\{L_{o m}(1+i), \min \left\{\tilde{q}_{m}, q_{r}\right\} p_{m}\right. \\
& \left.+s_{r} I_{r m}+s_{f} I_{f m}\right\}-L_{o m}\left(1+i^{\prime}\right) \\
I_{f m}=\tilde{q}_{m}- & \min \left\{\tilde{q}_{m}, q_{r}\right\}
\end{aligned}\right.
$$

In a similar way, we can get the maximum profit of bank when manufacture applied inventory mortgage.

$$
\left\{\begin{array}{l}
\max \left(\tilde{\Pi}_{L}^{\prime}\right)=\left(\min \left\{\tilde{q}_{m}, q_{r}\right\} p_{m}+s_{f} I_{f m}\right) \frac{i-i^{\prime}}{1+i} \\
L_{o m}=\left(\min \left\{\tilde{q}_{m}, q_{r}\right\} p_{m}+s_{f} I_{f m}\right) /(1+i) \\
L_{o m}(1+i) \geq \min \left\{\tilde{q}_{m}, q_{r}\right\} p_{m}+s_{r} I_{r m}+s_{f} I_{f m} \\
\geq L_{o m}\left(1+i^{\prime}\right)
\end{array}\right.
$$

\subsection{Manufacture Profit from Production}

Manufacture decides the expected most profit produce quantity $\tilde{q}_{m}$. Then manufacture will apply a loan of $L_{i m}$, the received loan of manufacture is $L_{m}=\min \left\{L_{o m}, L_{i m}\right\}$. We can get profit of manufacture as follow:

$$
\Pi_{m}=\min \left\{q_{m}, q_{r}\right\} p_{m}-\left(c_{l}+p_{r m} / \alpha\right) q_{m}-i L_{m}
$$

$L_{i m}$ is used to conquer the shortage of cash, because $i^{\prime}<i$, manufacture will maximize the usage of cash available of its own, at the end of production period, $x_{m}=0$. The initial cash of manufacture is $x_{m 0}$. By borrow from bank, manufacture have more opportunities to maximize $\tilde{\Pi}_{m}$

$$
\begin{aligned}
& \left\{\begin{array}{l}
\tilde{\Pi}_{m}=\tilde{q}_{m} p_{m}-\bar{c}_{m} q_{m}-i L_{i m} \\
\bar{c}_{m} q_{m}=x_{m 0}+L_{m} \\
\bar{c}_{m}=c_{l}+p_{r m} / \alpha
\end{array}\right. \\
& \begin{array}{l}
\tilde{\Pi}_{m}=q_{m} p_{m}-\bar{c}_{m} q_{m}-i L_{i m} \\
\quad=q_{m} p_{m}-x_{m 0}-(1+i) L_{i m}
\end{array} \\
& \tilde{\Pi}_{m}=q_{m} p_{m}-\bar{c}_{m} q_{m}-i L_{i m} \\
& =q_{m} p_{m}-\bar{c}_{m} q_{m}-i\left(\bar{c}_{m} q_{m}-x_{m 0}\right) \\
& =q_{m}\left[p_{m}-\bar{c}_{m}(1+i)\right]+i x_{m 0}
\end{aligned}
$$

From Equations (10) and (11), we can get the preconditions of loan are $q_{m} p_{m}>x_{m 0}$ and $p_{m}>\bar{c}_{m}(1+i)$. When the maximize profit is satisfied,

$$
L_{i m}=\max \left\{\bar{c}_{m} q_{m}-x_{m 0}, 0\right\} .
$$

\subsection{RMM Model and Conditions}

Based on the analysis both of bank and manufacture decisions, the cash investment and VaR value of both bank and manufacture should be balanced, we conclude the following RMM model:

$$
\min \left(\left|\operatorname{VaR}_{m} / x_{m 0}-\operatorname{VaR}_{b} / L_{m}\right|\right)
$$

Subject to:

$$
\left\{\begin{array}{l}
\begin{array}{rl}
L_{\text {om }}= & \left(\min \left\{\tilde{q}_{m}, q_{r}\right\} p_{m}+s_{f} I_{f m}\right) /(1+i) \\
L_{\text {om }}(1+i) \geq \min \left\{\tilde{q}_{m}, q_{r}\right\} p_{m}+s_{r} I_{r m}+s_{f} I_{f m} & \quad \geq L_{o m}\left(1+i^{\prime}\right)
\end{array} \\
L_{i m}=\max \left\{\bar{c}_{m} q_{m}-x_{m 0}, 0\right\} \\
\tilde{\Pi}_{m}=\tilde{q}_{m} p_{m}-\bar{c}_{m} q_{m}-i L_{i m} \\
\tilde{\Pi}_{L}=\min \left\{L_{o m}(1+i), \min \left\{\tilde{q}_{m}, q_{r}\right\} p_{m}\right\}-L_{o m}\left(1+i^{\prime}\right) \\
\operatorname{VaR}_{L}=E\left(\Pi_{L}\right)-\Pi_{L}^{*} \\
\operatorname{VaR}_{M}=E\left(\Pi_{M}\right)-\Pi_{M}^{*}
\end{array}\right.
$$

\subsection{Solutions to RMM Model}

We use matlab simulate the whole manufacture, retail and loan process with the model built above (Figure 1), the process of simulation shows as Figure 2. The demand for a consumer product and populate the model with $\mathrm{N}$ consumers. The basic demand function for each agent is well behaved:

$$
D_{i}=f_{i}-P
$$

The $f_{i}$ are selected at random and represent the heterogeneous tastes of customers. The sum of the individual demands $\sum_{i}^{N} D_{i}$ represents the whole market demand. For fashion goods, the size of the market can be assumed small compared to consumers' incomes and can therefore reasonably ignore the difficulties which the Sonneschein, Mantel, Debreu theorems (for example Sonnenschein 1972) raise for the shape of aggregate demand functions [8]. The demand curves for each individual customer are well behaved, and we assume that the sum of these is also well-behaved.

We calculate VaR follow four steps as follow:

1) Based on Equation (12), calculate the market demand series $\left\{q_{r 1}, q_{r 2}, q_{r 2} \cdots q_{r n}\right\}$ and then we can get expectations of $E\left(q_{r}\right) \quad\left(\tilde{q}_{m}=E\left(q_{r}\right)\right.$ which means the manufacture can predict the market demand in the long 


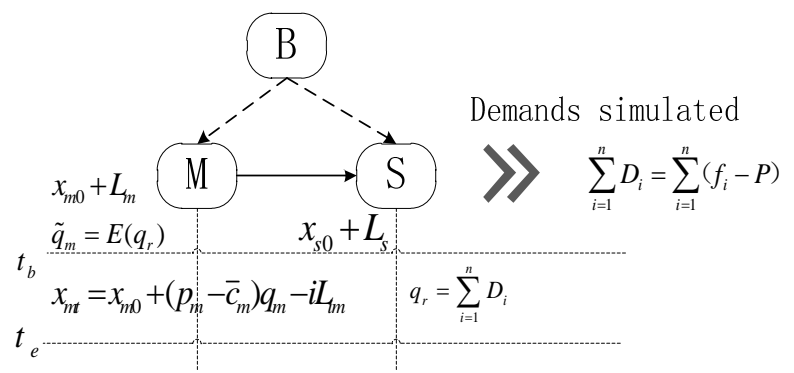

Figure 1. RMM model in simulation experiment.

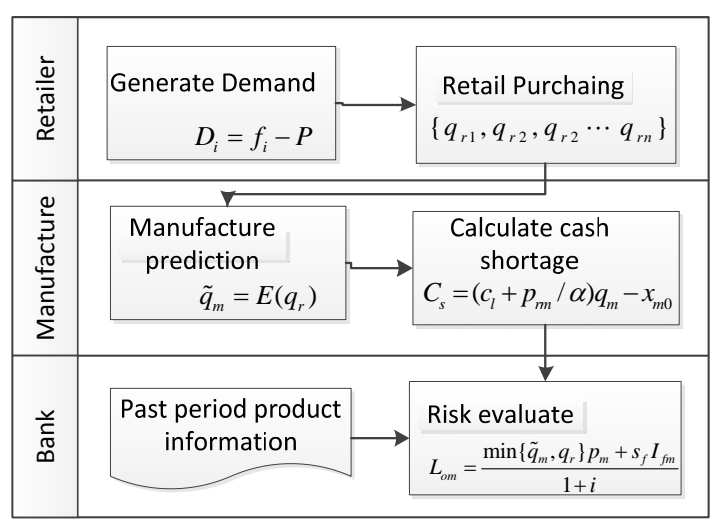

Figure 2. Flow of simulation experiment. run);

2) Select data basing on cash constrained conditions of $q_{m} p_{m}>x_{m 0}$ and $p_{m}>\bar{c}_{m}(1+i)$.

3) Calculate $\Pi_{L}$ and $\Pi_{m}$ based on Equations (5), (6), (7) and (8).

4) Calculate $\operatorname{VaR}_{m}$ and $\operatorname{VaR}_{b}$ based on Equations (1) and (2).

Necessary and sufficient conditions on the bivariate utility function vary according to the conditions imposed on the joint distribution of the risks. If only independent risks are considered, then any utility function which is concave in its first argument will satisfy the condition of risk aversion. If risk aversion is required for all possible pairs of risks, then the bivariate utility function has to be additively separable.

\section{Experiments Results (Table 1)}

The operating of supply chain is divided into a certain number of periods and the model with suitable demand forecasts is solved to yield scheduling/planning decisions for each period, and only those belonging to the first period are implemented. At the end of the first period, the state of the system, including inventory levels, is updated and the cycle is repeated with the horizon advanced by

Table 1. Typical data results of several experiments.

\begin{tabular}{|c|c|c|c|c|c|c|c|c|c|}
\hline$q_{m}$ & $p_{m}$ & $\bar{c}_{m}$ & $s_{f}$ & $\operatorname{VaR}_{M}$ & $\operatorname{VaR}_{M}^{\prime}$ & $\operatorname{VaR}_{L}$ & $\operatorname{VaR}_{L}^{\prime}$ & $\theta_{L}$ & $\theta_{L}^{\prime}$ \\
\hline 40000 & 40 & 28 & 20 & 3256.23 & 5675.20 & 7846.01 & 1102.30 & 0.71 & 0.16 \\
\hline 40000 & 80 & 50 & 40 & 1340.35 & 4521.32 & 5769.20 & 716.03 & 0.81 & 0.14 \\
\hline 40000 & 40 & 30 & 28 & 4341.35 & 6512.20 & 7524.63 & 1341.24 & 0.63 & 0.17 \\
\hline 30000 & 40 & 30 & 28 & 2571.92 & 4374.34 & 4529.84 & 857.34 & 0.64 & 0.16 \\
\hline 30000 & 80 & 28 & 30 & 1136.22 & 2456.43 & 4281.23 & 910.20 & 0.79 & 0.27 \\
\hline 30000 & 80 & 50 & 35 & 1263.28 & 4320.43 & 5472.21 & 702.16 & 0.81 & 0.14 \\
\hline
\end{tabular}

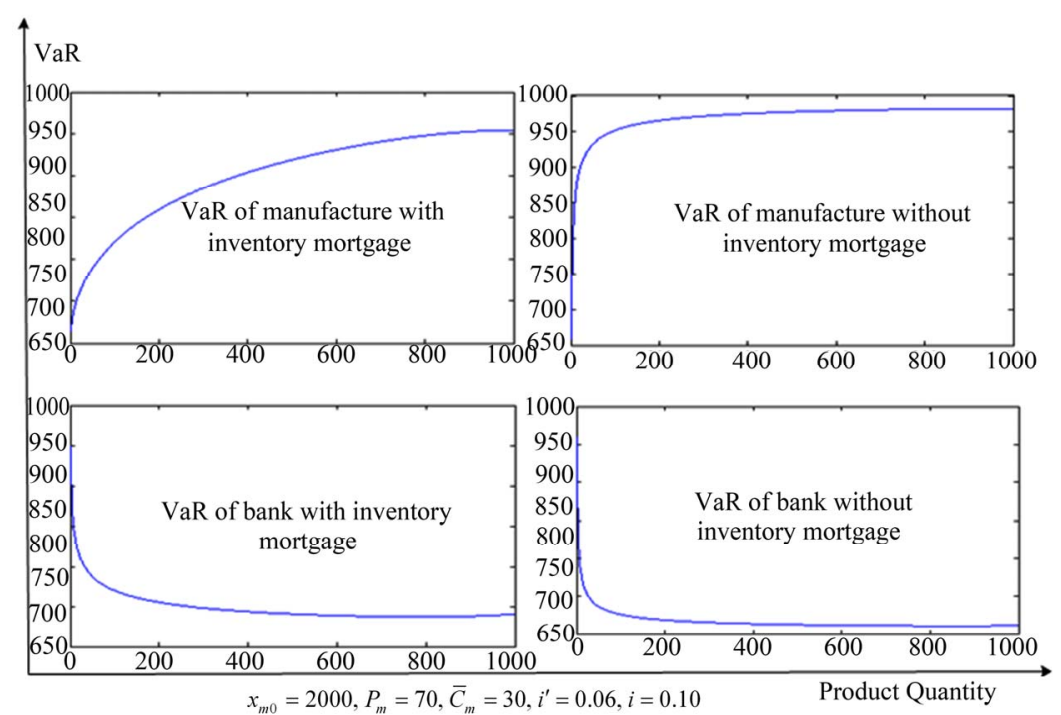

Figure 3. Relation curves between product quantity and VaR. 
one period considering the demand forecast for the new period, which is now available. Therefore, the deterministic formulation next described comprises a set of planning periods, and only the first one includes the detailed scheduling decisions with shorter time increments. Such detail period moves as the model is solved in time, thus the term rolling horizon.

Calculate VaR of both manufacture and bank, then standardize $\operatorname{VaR}$ to $[0,1]$, then we can get $\theta_{L}=\operatorname{VaR}_{L} /\left(\operatorname{VaR}_{L}+\operatorname{VaR}_{M}\right)$ basing on Equation (1) and (2). Get $\theta_{M}$ by $\theta_{M}=1-\theta_{L}$, Table 1 shows the typical data results of several experiments in computer simulation when $x_{m 0}=1000 、 i=0.10$ and $i^{\prime}=0.06$. With different initial variables, the bank $V a R$ will decrease when adopt inventory mortgage, the potential profit is growing. For the manufacture, after use inventory mortgage, VaR is larger than before. The potential income is growing because bank can offer more loans which reduce the manufacture shortage of cash, so the manufacture can produce more to maximum profit.

When the manufacture satisfies $q_{m} p_{m}>x_{m 0}$ and $p_{m}>\bar{c}_{m}(1+i)$, accompany with market demand increasing, the VaR of bank decrease because manufacture's capability of making profit. If using inventory mortgage, the VaR value for manufacture is increasing because more cash are put in producing and inventory(Figure 3).

\section{Conclusions}

We discussed manufacture and retail supply chain structure which both facing cash-constrain and a bank that finances the manufacturer. Supply chain inventory mortgage must satisfy preconditions of $q_{m} p_{m}>x_{m 0}$ and $p_{m}>\bar{c}_{m}(1+i)$, that is member of supply chain will use self-owned capital before using inventory mortgage, and the cost of loan must less than the profit rate. In inventory mortgage, both bank and manufacture are benefit because the risk migration. After migration of risk, it is more compatible with the information shared between supply chain member and bank. For supply chain members, they have more market information than bank in production operate process, after sharing inventory information with bank, this reduce the bank shortage information. So the migration of risk can help optimize the whole supply chain and bank.

\section{REFERENCES}

[1] J. L. Cavinato, "Identifying Interfirm Total Cost Advantages for Supply Chain Competitiveness,” International Journal of Purchasing and Material Management, Vol. 27, No. 4, pp. 10-15.

[2] J. A. Buzacott, R. Q. Zhang, "Inventory Management with Asset-Based Financing,” Management Science Vol. 50, No. 9, 2004, pp. 1274-1292. doi:10.1287/mnsc.1040.0278

[3] T. Y. Choi and Y. Hong, "Unveiling the Structure of Supply Networks: Case Studies in Honda, Acura, and Dailmer Chrysler,” Journal of Operations Management, Vol. 20, No. 5, 2002, pp. 469-494. doi:10.1016/S0272-6963(02)00025-6

[4] D. M. Lambert and M. C. Cooper, "Issues in Supply Chain Management,” Industrial Marketing Management, Vol. 29, No. 1, 2000, pp. 65-84. doi:10.1016/S0019-8501(99)00113-3

[5] N. R. Srinivasa Raghavan and V. K. Mishra, "Short-Term Financing in a Cash-Constrained Supply Chain,” International Journal of Production Economics, Vol. 11, No.14, 2009.

[6] D. Backus and J. Wright, "Cracking the conundrum," Brookings Papers on Economic Activity, Vol. 38, 2007, pp. 293-329.

[7] P. Jorion, "Value at Risk: The New Benchmark for Controlling Market Risk,” Irwin, Chicago, 1997.

[8] H. Sonnenschein, "Market Excess Demand Functions," Econometrica, Vol. 40, 1972, pp. 549-563. doi:10.2307/1913184 